\title{
Protease-Activated Receptor-2 Induces Myofibroblast Differentiation and Tissue Factor Up-Regulation during Bleomycin-Induced Lung Injury
}

\section{Potential Role in Pulmonary Fibrosis}

\author{
Keren Borensztajn, ${ }^{\star \dagger}$ Paul Bresser, ${ }^{\ddagger}$ \\ Chris van der Loos, ${ }^{\S}$ Ilze Bot, ${ }^{\pi}$ \\ Bernt van den Blink," Michael A. den Bakker, ${ }^{* \star}$ \\ Joost Daalhuisen, ${ }^{*}$ Angelique P. Groot, ${ }^{*}$ \\ Maikel P. Peppelenbosch, ${ }^{+, \dagger+}$ \\ Jan H. von der Thüsen, ${ }^{\S \neq \ddagger}$ and C. Arnold Spek* \\ From the Center for Experimental and Molecular Medicine,* \\ and the Departments of Pulmonology, and Pathology,, \\ Academic Medical Center, Amsterdam, The Netherlands; the \\ Department of Cell Biology, ${ }^{\dagger}$ University of Groningen, Groningen, \\ The Netherlands; the Division of Biopharmaceutics The Leiden \\ Amsterdam Center for Drug Research, " Leiden University, \\ Gorlaeus Laboratories, Leiden, The Netherlands; the Departments \\ of Pulmonology," Pathology,* and Gastroenterology and

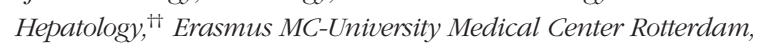 \\ Rotterdam, The Netherlands; and the Department of Histopathology, \\ Royal Brompton Hospital, London, United Kingdom
}

Idiopathic pulmonary fibrosis constitutes the most devastating form of fibrotic lung disorders and remains refractory to current therapies. The coagulation cascade is frequently activated during pulmonary fibrosis, but this observation has so far resisted a mechanistic explanation. Recent data suggest that protease-activated receptor (PAR)-2, a receptor activated by (among others) coagulation factor (F)Xa, plays a key role in fibrotic disease; consequently, we assessed the role of PAR-2 in the development of pulmonary fibrosis in this study. We show that PAR-2 is up-regulated in the lungs of patients with idiopathic pulmonary fibrosis and that bronchoalveolar lavage fluid from these patients displays increased procoagulant activity that triggers fibroblast survival. Using a bleomycin model of pulmonary fibrosis, we show that bleomycin induces PAR-2 expression, as well as both myofibroblast differentiation and collagen synthesis. In PAR-2-/ - mice, both the extent and severity of fibrotic lesions are reduced, whereas myofibroblast differentiation is diminished and collagen expression is decreased. Moreover, fibrin deposition in the lungs of fibrotic PAR-2-/- mice is reduced compared with wild-type mice due to differential tissue factor $\mathbf{e x}$ pression in response to bleomycin. Taken together, these results suggest an important role for PAR-2 in the development of pulmonary fibrosis, and the inhibition of the PAR-2-coagulation axis may provide a novel therapeutic approach to treat this devastating disease. (Am J Pathol 2010, 177:2753-2764; DOI: 10.2353/ajpath.2010.091107)

Idiopathic pulmonary fibrosis (IPF) constitutes the most devastating form of fibrotic idiopathic interstitial pneumonias. ${ }^{1,2}$ It generally evolves toward a destructive and irreversible fibrosis, responsible for respiratory failure. The median survival is 2 to 5 years. ${ }^{3,4}$ Although substantial efforts led to considerable improvement in diagnosing the diseases and predicting the outcome, fibrotic lung diseases remain generally refractory to current available pharmacological therapies. ${ }^{4,5}$ Interestingly, coagulation cascade activation is frequently observed in lungs of patients with fibrotic lung diseases. Enhanced expression of tissue factor (TF) and intra-alveolar fibrin deposition were demonstrated in lung biopsy specimens from patients with pulmonary fibrosis. ${ }^{6-9}$ Procoagulant activity was demonstrated in bronchoalveolar lavage fluid (BALF) of patients with various forms of pulmonary fibrosis. More-

\footnotetext{
Supported by the TI-Pharma project number T1-215.

Accepted for publication August 9, 2010

Supplemental material for this article can be found on http://ajp. amjpathol.org.

Address reprint requests to Keren Borensztajn, Ph.D., Center for Experimental and Molecular Medicine, Academic Medical Center, Meibergdreef 9 NL-1105 AZ, Amsterdam, The Netherlands. E-mail: K.S.Borensztajn@ amc.uva.nl.
} 
over, local procoagulant activity was demonstrated in patients with acute lung injury. ${ }^{6,8-10}$ The mechanistic link between coagulation activation and pulmonary fibrosis, however, remains elusive. Recent data suggest that protease-activated receptor 2 (PAR-2), a cellular receptor activated by (among others) coagulation factor $(\mathrm{F}) \mathrm{Xa}$, is an important player in fibrotic disease. PAR-2 triggers fibroproliferative responses in vitro ${ }^{11-13}$ and is highly expressed in fibrotic disorders. ${ }^{12}$ This study explores the role of blood coagulation factor driven PAR-2 activation in pulmonary fibrosis. We show that PAR-2 is up-regulated in the lung of IPF patients and that BALF of these patients displays increased procoagulant activity and enhances fibroblast survival. Using a mouse model of bleomycininduced lung fibrosis, we show that PAR-2 deficiency is protective. Moreover, BALF of bleomycin-treated PAR-2 deficient mice less effectively induced fibroblast survival compared to BALF of wild-type treated mice; and bleomycin induced less coagulation activation in PAR-2 deficient mice. Taken together, PAR-2 seems to contribute to the progression of pulmonary fibrosis, and inhibition of the PAR-2-coagulation axis may be clinically relevant.

\section{Materials and Methods}

\section{Patients}

Eight patients with biopsy-proven IPF (mean age $67 \pm 6$ yrs) were included in this study; IPF was defined according to international guidelines (American Thoracic Society/European Respiratory Society ${ }^{14}$ ). Pathology specimens were judged according to the criteria described by Katzenstein and Myers. ${ }^{1}$ In the IPF patients, bronchoalveolar lavage was performed as part of the routine workup; the procedure of bronchoalveolar lavage was previously described. ${ }^{15}$ BALF from nine healthy volunteers (mean age $32 \pm 8$ yrs) who had participated in a previously reported study ${ }^{15}$ served as controls. From five patients, enough BALF was available to study in vitro stimulation of human lung fibroblast. Control BALF was obtained from healthy volunteers. The study was approved by the Institutional Scientific and Ethics committees. Written informed consent was obtained from all subjects.

\section{Assays}

The levels of thrombin-antithrombin and that of soluble TF were measured in the BALF of IPF patients and controls using specific commercially available enzyme-linked immunosorbent assays (thrombin-antithrombin complex: Behringwerke AG, Marburg, Germany; soluble TF: American Diagnostics, Greenwich, CT) following the manufacturer's instructions.

\section{Animals}

Ten-week-old wild-type C57BI/6 mice were purchased from Charles River (Someren, the Netherlands). PAR-2 deficient (PAR-2-/-) C57BI/6 mice were originally pro- vided by Jackson Laboratories (Maine) and bred at the animal care facility of the Academic Medical Center. All mice were maintained according to institutional guidelines. Animal procedures were carried out in compliance with the Institutional Standards for Humane Care and Use of Laboratory Animals. The Animal Care and Use Committee of the Academic Medical Center (Amsterdam, the Netherlands) approved all experiments. In each experimental group, eight mice were used. For baseline characteristics, four mice per genotype were used.

\section{Experimental Model of Pulmonary Fibrosis}

Bleomycin sulfate $(1 \mathrm{mg} / \mathrm{kg}$ body weight in $45 \mu \mathrm{l}$ of saline as described in ${ }^{16}$; Sigma, St-Louis, MO) was administrated by a single intratracheal injection under anesthesia. Control animals received an intratracheal saline injection. Mice were sacrificed 7 and 14 days after bleomycin instillation.

\section{$B A L F$}

Bronchoalveolar lavage was performed by instilling four times $0.3 \mathrm{ml}$ aliquots of saline by a 22-gauge Abbocath-T catheter into the trachea via a midline incision. ${ }^{17}$

\section{Total Cell Number and Differential Cell Count}

Total BALF cell numbers were assessed with a BurkerTurk hemocytometer (Emergo, Landsmeer, The Netherlands). Briefly, cells were pelleted by centrifugation, then resuspended in PBS and counted according to the manufacturer's recommendations. Differential BALF cell counts were performed by cytospins prepared by centrifuging $100 \mu \mathrm{l}$ of BALF suspensions containing 200,000 cells $/ \mathrm{ml}$. Slides were air dried and stained with Giemsa. Cells were identified as macrophages/monocytes, neutrophils, or lymphocytes, and data were expressed in absolute numbers.

\section{Histopathological Assessment of Pulmonary Fibrosis}

The right lung of each animal was excised 7 or 14 days after bleomycin or saline treatment. Following fixation, entire mouse lungs were embedded in paraffin. Fourmicron thick sections were stained with H\&E, Masson's trichrome, and Sirius red, according to routine procedures. In H\&E-stained lung sections, three systems were used to assess fibrosis (see Table $1^{18,19}$ ). For each scoring, observers blinded to the treatment group and genotype examined between 4 and 16 fields in all lung lobes (depending on the size and the homogeneity of the histological changes) using light microscopy ( $\times 200$ magnification). Fields were examined to cover each entire lobe and were discarded if nonrepresentative areas such as airway lumen occupied $>50 \%$ of the field of view. The mean score for each lobe was expressed as the average of scores determined in each field. The first scoring sys- 
Table 1. Criteria for Histologic Fibrosis Score of Lung

\begin{tabular}{ccl}
\hline & Score & Description \\
\hline Fibrosis (Ashcroft score, according & 0 & Normal lung \\
to Ashcroft et $\mathrm{al}^{18}$ ) & 1 & Minimal fibrous thickening of alveolar or bronchiolar walls \\
& 2 & Moderate thickening of walls without obvious damage to \\
lung architecture & Increased fibrosis with definite damage to lung structure \\
& 3 & and formation of fibrous band or small fibrous masses \\
Percent involvement & 4 & Severe distortion of structure and large fibrotic areas, \\
& 5 & "honeycombing" \\
& 7 & $0-10 \%$ of the section \\
& 0 & $10-25 \%$ of section \\
& 1 & $25-50 \%$ of section \\
\hline
\end{tabular}

Adapted from Theiss et al. ${ }^{19}$

tem was used to determine the extent of the fibrotic lesions. For each field, the surface of fibrosis was rated as a percentage of the total surface of the field, and the mean percentage (average of percentages determined in each field) reflected the percentage fibrotic area for the lung. Second, the severity of the lesions was determined by using the Ashcroft scoring system ${ }^{18}$ (see Table $\left.1^{18,19}\right)$. The severity of the fibrotic changes in each lung section was assessed as a mean score of severity from observed microscopic fields. An average of 15 fields within each lung section were observed at a magnification of $\times 200$ in each successive field, and each field was assessed individually for the severity of fibrotic changes and allotted a score from 0 (normal) to 8 (total fibrosis) using a predetermined scale of severity (numerical fibrotic scale). After examination of the whole section, the mean of the scores from all fields was taken as the fibrotic score. To prevent observer bias, all histological specimens were randomly numbered and interpreted in a blinded fashion. Finally, to determine a mean histological score taking in account both the severity and the extent of the fibrotic lesions, a mean score ranging from 0 to 4 to reflect $0 \%-100 \%$ mean fibrotic percentage was assessed for each section, and multiplied by the mean Ashcroft score.

\section{Cytokine/Chemokine Assays}

Interleukin-6, monocyte chemotactic protein-1, interferon, and tumor necrosis factor were measured using the BD Cytometric Bead Array Mouse Inflammation Kit (Becton Dickinson, Lincoln Park, NJ) following the manufacturer's instructions. Detection limits were $10 \mathrm{pg} / \mathrm{ml}$.

\section{Immunohistochemistry}

For immunohistochemistry, 4- $\mu \mathrm{m}$ (murine) or 5- $\mu \mathrm{m}$ (human) sections were first deparaffinized and rehydrated. Endogenous peroxidase activity was quenched with $0.3 \% \mathrm{H}_{2} \mathrm{O}_{2}$ in methanol, and for PAR-1 and PAR-2 staining heat-induced epitope retrieval antigen retrieval was performed using $10 \mathrm{mmol} / \mathrm{L}$ citrate buffer $[\mathrm{pH} 6.0$, for 20 minutes. at $98^{\circ} \mathrm{C}$ in a pretreatment module (Thermo/Lab- vision, Fremont, CA)]. PAR-1 and PAR-2 stainings were performed with 1:150 anti-PAR-1 $\mathrm{H} 111$ (48 hours at $4^{\circ} \mathrm{C}$ ) or 1:200 anti-PAR-2 SAM11 (24 hours at $4^{\circ} \mathrm{C}$ ) antibody (Santa Cruz Biotechnology, Santa Cruz, CA). Smooth muscle actin (aSMA) was visualized using anti-aSMA-1 clone 1A4 (1:500, 1 hour at room temperature, SigmaAldrich, St. Louis, MO). A two- or three-step horseradish peroxidase-conjugated polymer detection system (ImmunoLogic, Duiven, The Netherlands) was applied for visualization, using appropriate secondary antibodies and diaminobenzidine staining. Slides were photographed on a Zeiss Axioskop (Zeiss, Jena, Germany) with a Sony DXC950P CCD camera (Sony, Tokyo, Japan). Fibrin and Ly-6 stainings were performed as described previously. ${ }^{20}$ Fibrin staining was graded in a blinded fashion on a 0 to 3 scale in which 0 indicates a lung section with no staining, whereas 1 indicates weak staining, 2 indicates median staining, and 3 indicates intense staining. The number of neutrophils as assessed by LY-6 was scored on 10 microscopic fields at a magnification of $\times 40$.

\section{Western Blot}

Pulverized lung tissues were lysed in Laemmli lysis buffer, incubated for 5 minutes at $95^{\circ} \mathrm{C}$, and whole cell lysates were separated by $10 \%$ SDS-polyacrylamide gel electrophoresis. After electrophoresis, proteins were transferred to an immobilon-P polyvinylidene difluoride membrane (Millipore, Billerica, MA). Membranes were incubated overnight at $4^{\circ} \mathrm{C}$ with primary antibodies against $\alpha$-actin, $\beta$-actin, collagen, PAR-2 (SAM11) (all Santa Cruz, CA), total p42/44 mitogen-activated protein kinase, and epidermal growth factor receptor (Cell Signaling Technology, Beverly, MA). All secondary antibodies were horseradish peroxidase-conjugated from DakoCytomation (Glostrup, Denmark). Blots were imaged using Lumilight Plus ECL substrate from Roche (Basel, Switzerland) on a GeneGnome imager (Syngene, Cambridge, UK). For quantification, densitometry was performed using a GeneTools software (Syngene, Cambridge, UK). Briefly, raw volumes corresponding to the histogram function of the band corresponding to the pro- 
tein of interest were corrected for those of the loading control ( $\beta$-actin or epidermal growth factor receptor as indicated). Data are expressed as mean \pm SEM of Western blots which were repeated three times.

\section{Cell Culture}

Murine myoblasts C2C12 (CRL-1772), human non-small cell lung cancer cells A549 (CCL-185) and human lung fibroblasts MRC-5 (CCL-171) were purchased from American Type Culture Collection (ATCC), Rockville, MD. Primary murine lung fibroblasts were isolated from wildtype and PAR-2-1- mouse lungs as described in. ${ }^{21}$ Cells were maintained in Dulbecco's modified Eagle's medium or RPMI (A549 cells) supplemented with 10\% fetal calf serum and passed according to routine procedures. Unless stated otherwise, cells were washed twice with PBS, serum-starved for 4 hours and subsequently stimulated as described.

\section{Epithelial Permeability Assays}

A549 cells were used for this assay, as these pulmonary type-II epithelial cell line derived from an individual with alveolar cell carcinoma retained many of the characteristics of normal type-II epithelial cells, such as surfactant production, cytoplasmic multilamellar inclusion bodies, and cuboidal appearance. ${ }^{22}$ The permeability of A549 monolayers was analyzed in a dual chamber system by measuring the flux of Evans blue-labeled bovine serum albumin (respectively, Sigma, St. Louis, MO, and Calbiochem) across the monolayer as detailed in. ${ }^{23}$ Briefly, A549 cells were plated on Transwell polycarbonate membranes of $0.4-\mu \mathrm{m}$ pore size (Corning Inc., Corning, NY) and grown to confluence. Subsequently, cells were serum-starved overnight prior stimulation with 100 $\mu \mathrm{mol} / \mathrm{L}$ PAR-2 agonist peptide (Anaspec, CA) or PBS as a control. Samples (10 $\mu \mathrm{l}$ ) were taken from the lower chamber at the indicated time points and after 10-fold dilution Evans Blue-bovine serum albumin concentrations were measured at $620 \mathrm{~nm}$ using a plate reader spectrophotometer.

\section{Viability Assay}

Cells were seeded in 96-well plates in $100 \mu$ l of the indicated murine (C2C12 cells, wild-type and PAR2-/- fibroblasts) or human (MRC-5 cells) BALFs to determine their properties on cell viability. Cell viability was determined at the indicated intervals using a 3-(4,5-dimethylthiazol-2-yl)-2,5-diphenyltetrazolium (MTT) assay, as described before. ${ }^{13}$ Tick anticoagulant peptide (TAP) and hirudin (Calbiochem, San Diego, CA) were used at a concentration of $200 \mathrm{nmol} / \mathrm{L}$ (TAP) and $100 \mathrm{nmol} / \mathrm{L}$ (hirudin).

\section{Statistical Analysis}

Statistical analyses were conducted using GraphPad Prism version 3.00 (GraphPad Software, San Diego, CA).
The levels in control (saline-treated) animals were set at $100 \%$. Data are expressed as mean \pm SEM. Comparisons between two groups were analyzed using two tailed unpaired $t$-tests when the data where demonstrated to be normally distributed, otherwise Mann-Whitney analysis was performed. $P$ values of $<0.05$ were considered to indicate a statistically significant difference between two groups.

\section{Results}

To confirm and expand previous data on the pro-coagulant activity in BALF of IPF patients, we measured thrombin-anti-thrombin complex levels, which are a hallmark of the activation of the coagulation cascade, in the BALF of eight IPF patients. As shown in Figure 1A, BALF thrombin-anti-thrombin complex was increased $55 \%$ in IPF patients when compared with healthy volunteers $(n=9)$ referred to as controls. Furthermore, BALF levels of soluble TF were significantly increased by about $50 \%$ in IPF patients compared to controls (Figure 1B).

To determine whether coagulation cascade activation in IPF patients was an epiphenomenon, or may play a role in the ongoing progression of fibrosis, we next assessed the functional consequences of human lung fibroblast stimulation with BALF with respect to cell survival. Indeed, both thrombin and FXa have been shown to have a
A

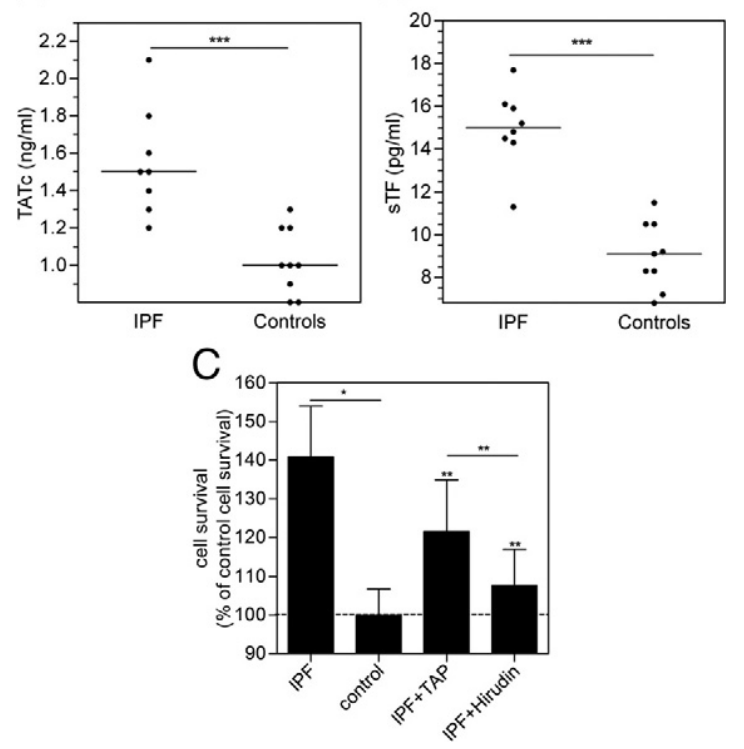

Figure 1. Coagulation cascade activation in the BALF of patients with IPF triggers a mitogenic response. Thrombin-antithrombin complex (A) and soluble TF (sTF) (B) levels in BALF of either patients with IPF or healthy volunteers (controls). Results are presented as scatter dot plots corresponding to the values found for each subject. The horizontal line represents the median for each group. ${ }^{* * * *} P<0.0005$. C: Survival of human lung fibroblasts induced by 24-hour incubation with BALF from IPF patients $(n=5)$ or healthy volunteers (controls; $n=7$ ), in the presence or absence of the FXa inhibitor TAP or the thrombin inhibitor hirudin. Data are from two independent experiments and are expressed as mean \pm SEM of percentage of survival induced by BALF of healthy volunteers (control). ${ }^{*} P<0.05$, comparing survival induced by IPF BALF versus control BALF, and $* * P<0.05$ comparing survival induced by IPF BALF versus IPF+TAP BALF, or IPF BALF versus IPF + Hirudin BALF. There were no significant differences between $\mathrm{IPF}+$ TAP BALF or IPF + Hirudin BALF and control BALF. 
A

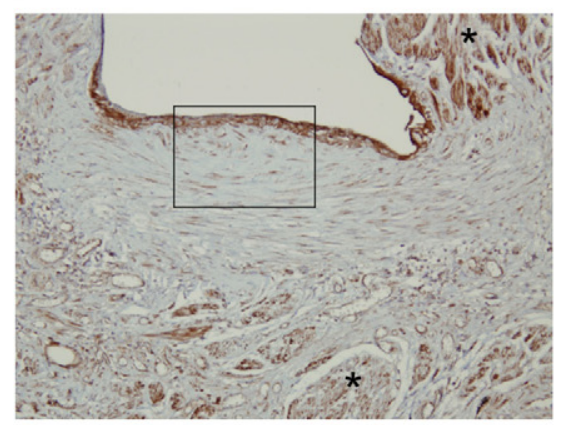

C

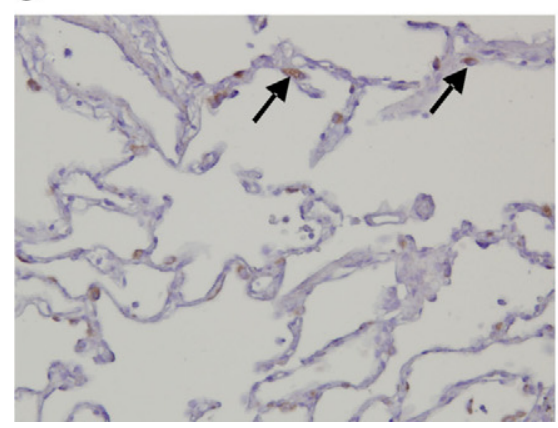

B

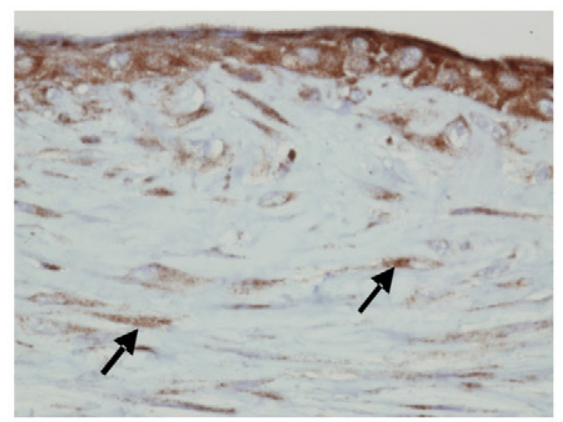

D

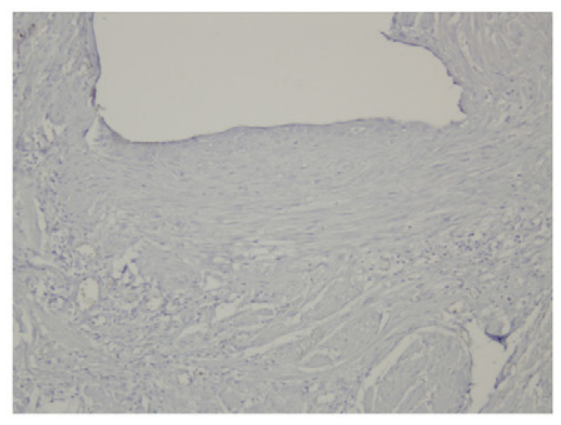

Figure 2. Expression of PAR-2 in lung biopsies of patients with IPF. Immunohistochemical PAR-2 staining of fibrotic regions of the lung of patients with IPF (A and $\mathbf{B}$ ) showing enhanced PAR-2 expression in smooth muscle cells (Asterisk in A $\times 100$ ), epithelial cells overlying a fibroblast focus (A, inset and $\mathbf{B}, \times 400)$, and in (myo)fibroblasts of this focus (B, arrows). In non-fibrotic parts of the lung $(\mathbf{C}, \times 200)$, only sparse PAR-2 expression was observed in type II alveolar cells (arrows). D and E represent isotype control staining.

\section{E}

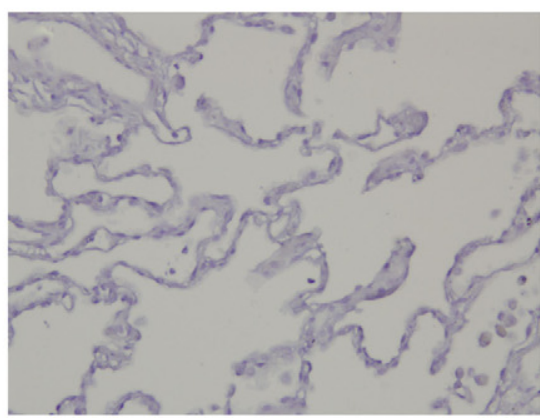

proliferative effect on fibroblasts. ${ }^{6,13,16,24}$ As shown in Figure 1C, BALF of IPF patients enhanced fibroblast survival by $40 \%$ as compared to BALF of controls. Strikingly, this increased viability induced by the BALF of IPF patients was significantly reduced by the FXa inhibitor TAP (to $21 \%$ ), and by the thrombin inhibitor hirudin (to $8 \%$ ). Incubation of fibroblasts with TAP or hirudin in the absence of BALF did not affect cell survival (data not shown).

Lung biopsies of IPF patients showed characteristics of usual interstitial pneumonia, such as the abundant presence of characteristic fibroblast foci. Immunohistochemical staining of lung biopsies from these IPF patients showed prominent PAR-2 expression, especially on smooth muscle cells, but also on epithelial cells overlying a fibroblast focus, and in (myo)fibroblasts of these foci (Figure 2, A and B). In contrast, only sparse staining of alveolar type II cells was observed in the nonfibrotic part of the lung of these patients (Figure 2C). There was no detectable signal for similar sections stained with an isotype-specific control antibody (Figure 2, D and E). To assess the specificity of the PAR-2 antibody, we compared PAR-2 and PAR-1 expression and cellular localization in IPF biopsies. As shown in Supplemental Figure S1 (at http://ajp.amjpathol.org/), fibrotic tissue primarily seemed to show PAR-1 overexpression in epithelial cells in inflamed areas (rather than in epithelial cells overlying fibroblastic foci (Supplemental Figure S1, A and B, at http://ajp.amjpathol.org/) and on macrophages, while in the non fibrotic parts of the lungs, PAR-1 was mainly expressed by type II pneumocytes (Supplemental Figure S1C at http://ajp.amjpathol.org/). Overall, these data suggest that PAR-2 might specifically contribute to the development of pulmonary fibrosis in IPF, support a role for the coagulation system in this, and prompted us to inves- tigate the role of PAR-2 in a murine model of bleomycininduced pulmonary injury.

Bleomycin treatment of wild-type mice elicited alveolar wall thickening due to inflammation and fibrosis, eventually culminating in tissue remodeling and 'honeycomb' changes akin to those observed in usual interstitial pneumonia patients (Figure 3A). These changes were not observed in the saline-treated animals (Figure 3B). In line, Masson's trichrome staining demonstrates patchy, well-demarcated areas of fibrosis with significant collagen deposition in the wild-type mice (Figure 3, D and G), together with strong $\alpha$-actin expression (Figure $3 \mathrm{~J}$ ). In contrast, Masson's trichrome staining displays delicate interalveolar septa without significant presence of collagen in saline treated animals (Figure 3, E and H). Additionally, we assessed PAR-2 expression in wild-type mice treated with bleomycin to determine whether PAR-2 expression was up-regulated as observed in the biopsies of the IPF patients. Indeed, pathological features were accompanied by significantly increased PAR-2 levels in lung homogenates of bleomycin treated mice as compared to saline treated mice (Figure 3I). Immunohistochemical staining showed that bleomycin induced PAR-2 expression in type 2 pneumocytes, but also in reactive epithelial cells at the advancing edge of fibrosis, mononuclear cells and spindle-shaped cells in areas of fibrosis [possibly (myo)fibroblasts] (Figure 3, C and F). In contrast, PAR-2 only stains strongly positive in type 2 pneumocytes of saline treated animals (Figure $3 \mathrm{C}$ ). In line, bleomycin treatment of PAR-2-/- mice resulted in significantly reduced histological changes (as determined by a histological score adapted from Theiss et al., $2005,{ }^{19}$ which takes in account not only the severity of the lesions (which are routinely assessed by the Ashcroft score, ${ }^{18}$ but also the extent of these fibrotic lesions) as 
A

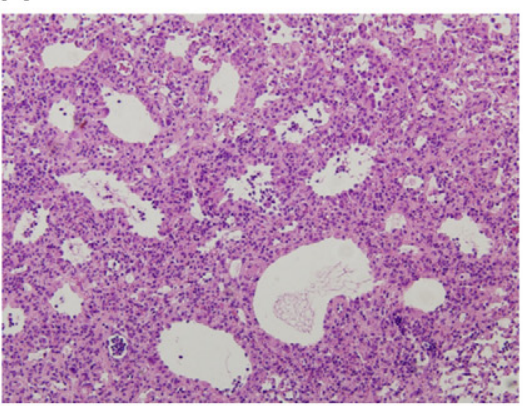

D

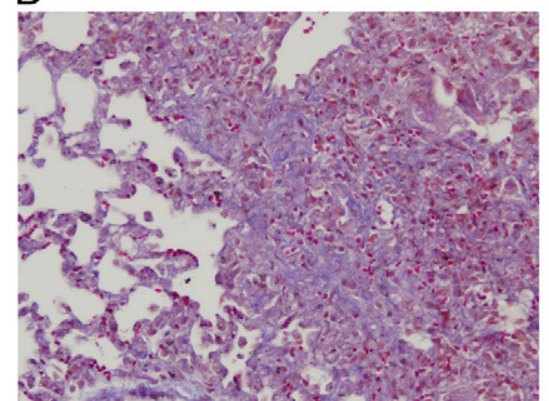

G

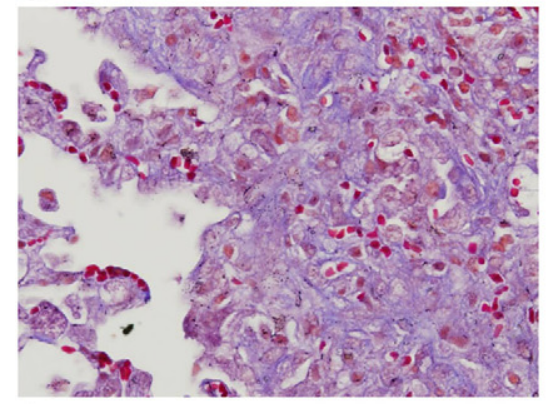

J

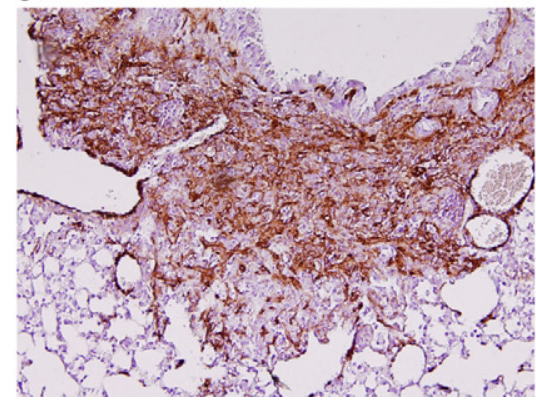

B

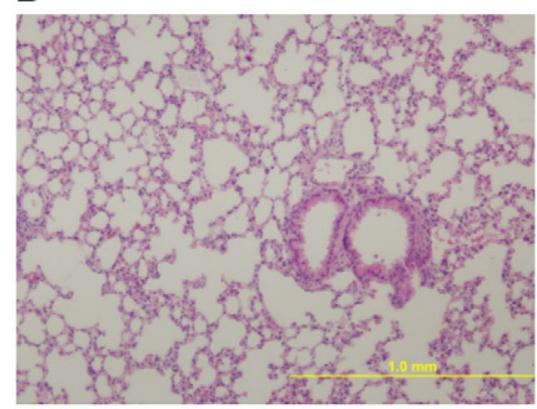

E

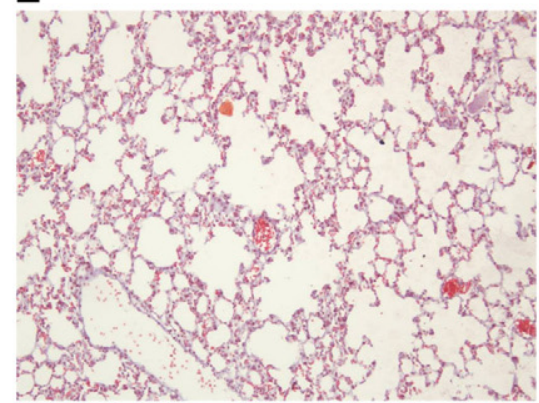

$\mathrm{H}$

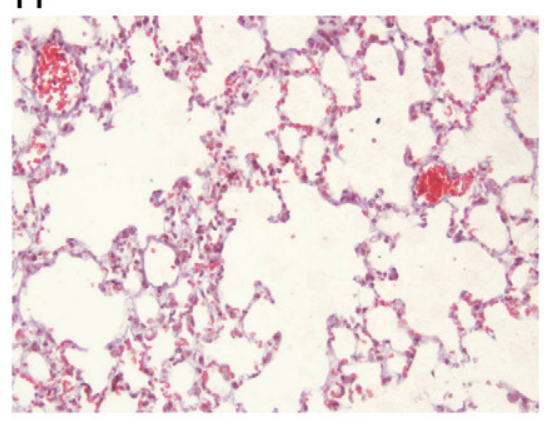

C

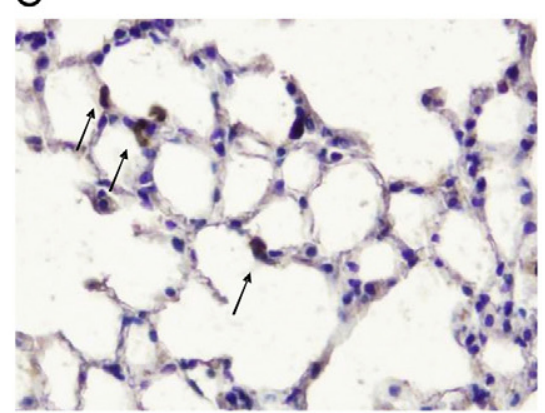

$\mathrm{F}$

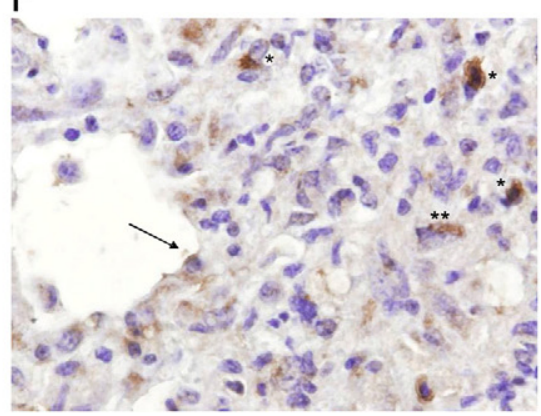

I
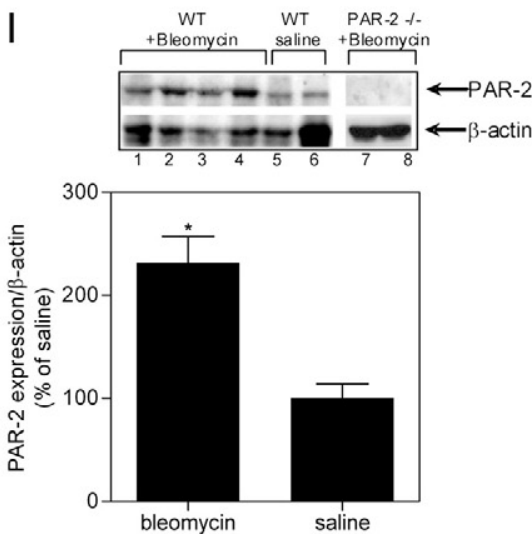

Figure 3. Bleomycin induces fibrosis and PAR-2 up-regulation in the lungs of wild-type mice. Lung tissue sections 14 days after bleomycin $(\mathbf{A}, \mathbf{D}, \mathbf{F}, \mathbf{G}$, and $\mathbf{J})$ or saline $(\mathbf{B}, \mathbf{C}, \mathbf{E}$, and $\mathbf{H})$ administration. $\mathbf{A}$ and $\mathbf{B}: \mathrm{H} \& \mathrm{E}$ $(\times 100)$. C and F: PAR-2 staining of type 2 pneumocytes and in reactive epithelial cells at the advancing edge of fibrosis (arrow), mononuclear cells (Asterisk) and spindle-shaped cells in areas of fibrosis (Double Asterisks; C, $\times 400)$ and, in type II pneumocytes (arrows) of saline treated mice $(\mathbf{F}, \times 400)$. D, $\mathbf{E}, \mathbf{G}$, and $\mathbf{H}$ : Masson's trichrome staining [ $\times 200(\mathbf{D}$ and $\mathbf{E})$ and $\times 400$ ( $\mathbf{G}$ and $\mathbf{H})$; collagen in blue]. J: aSMA staining $(\times 100)$. I, top: Representative Western blot analysis of PAR-2 expression in pulverized lungs of wild-type mice 14 days after bleomycin administration (lanes 1-4); wild-type mice treated with saline (lanes 5 and 6); and PAR-2-/- mice 14 days after bleomycin administration (lanes 7-8). $\beta$-actin serves as a loading control (bottom). Quantification of PAR-2 expression in wild-type mice 14 days after bleomycin or saline treatment. ${ }^{*} P<0.005$ for bleomycin- versus saline-treated mice.

compared to wild-type animals (Figure 4, A and B). More specifically, PAR-2 deficiency reduced the area of interstitial fibrotic lesions by $69 \%$ and $45 \%, 7$ and 14 days after bleomycin treatment, respectively (Supplemental Figure S2A at http://ajp.amjpathol.org/). Moreover, as determined by the Ashcroft scoring system, PAR-2 deficiency reduced the severity of the lesions induced by bleomycin exposure (Supplemental Figure S2B at $h t t p: / /$ ajp.amjpathol.org/; from $3.7 \pm 0.4$ and $4.8 \pm 0.3$ to $2 \pm 0.2$ and $3.5 \pm 0.1$ in wild-type and PAR-2-/- mice, 7 and 14 days after bleomycin treatment, respectively). Combining these data in a mean histological score calculated using the criteria indicated in Table 1, we showed that PAR-2 deficiency reduced pulmonary fibrosis, by about $66 \%$ and $50 \%$, after 7 and 14 days, respectively (Figure 4C). Noteworthy, the difference between PAR-2 deficient and wildtype mice was slightly, but consistently, reduced after 14 days of treatment compared to 7 days treatment, emphasizing that pulmonary fibrosis is complex and involves many pathways of which PAR-2 appears an important one.

A potential mechanism by which PAR-2 activation may impact on lung pathology would be by inducing fibroblast differentiation into myofibroblasts. In a murine model of kidney fibrosis, ${ }^{25}$ the expression of PAR-2 and $\alpha$-SMA (a hallmark of myofibroblast differentiation), was correlated. In keeping with this observation, we recently showed that 
A

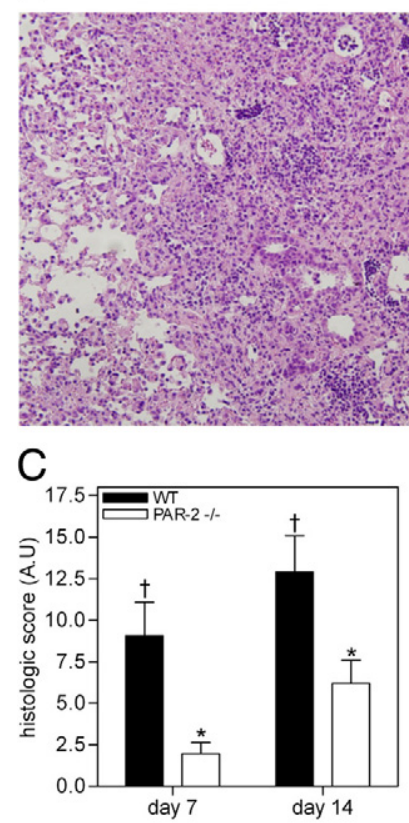

B

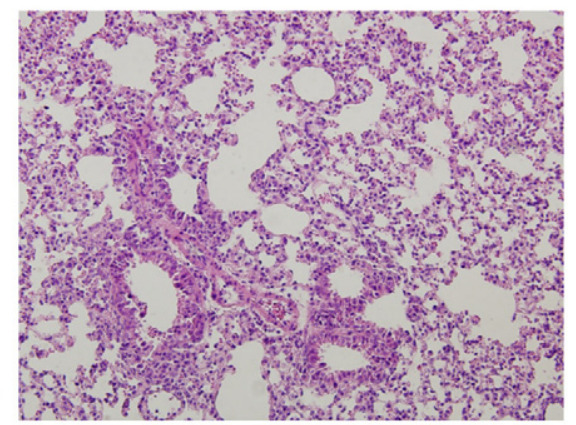

D

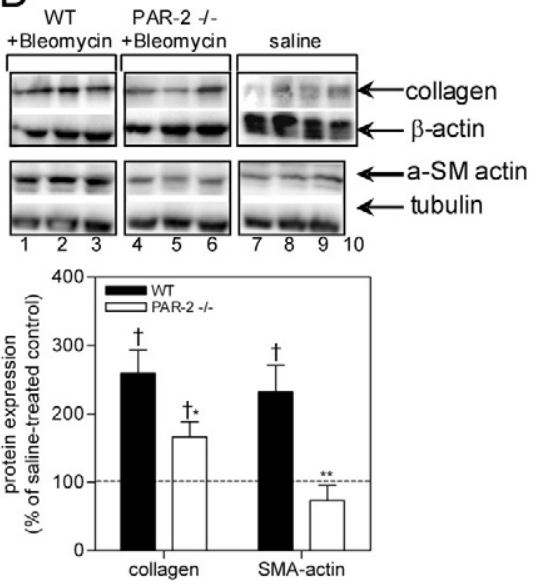

Figure 4. PAR-2 deficiency affords protection from bleomycin-induced pulmonary fibrosis. A and B: PAR-2 deficiency reduces the development of pulmonary fibrosis induced by intratracheal bleomycin instillation. A: In wild-type mice, there was marked accumulation of inflammatory cells and collagen, while histologica changes were markedly attenuated in PAR$2-/-$ mice (B). C: Histological analysis of pulmonary fibrosis in wild-type and PAR-2 $-/-$ mice in response to bleomycin instillation. Shown is the mean histological score 7 and 14 days after bleomycin treatment. Wild-type mice, $n=7$; PAR- $-/-$ mice, $n=8$. D: PAR-2 deficiency impairs fibroblast differentiation and reduces extracellular matrix deposition. Top Western blot analysis of collagen and $\alpha$-SMA expression in wild-type (lanes 1-3 and 9-10) and PAR-2-/- mice (lanes 4-8) 14 days after bleomycin (lanes 1-6) or saline treatment (lanes 7-10). $\beta$-actin serves as a loading control. Bottom: Quantification of protein expression. The dotted lines represent the mean expression of the different proteins in salinetreated mice. Data represent the mean \pm SEM ( $n=5-8$ mice per group). ${ }^{\dagger} P<0.05$ and ${ }^{\dagger t} P<$ 0.005 for bleomycin versus saline treated mice. ${ }^{*} P<0.05$ and ${ }^{* *} P<0.005$ for bleomycin treated wild-type versus PAR-2-/- mice. ns, not significant.
FXa-induced PAR-2 activation leads to $\alpha$-SMA expression by fibroblasts. ${ }^{13}$ Hence, we examined the modulation of pulmonary $\alpha$-SMA expression in response to bleomycin administration in wild-type and PAR-2-/- mice. The expression of $\alpha$-SMA was strongly enhanced by $131 \%$ in wild-type mice in response to bleomycin, whereas $\alpha$-SMA expression in PAR-2-1- mice was similar in bleomycin and saline-treated mice (Figure 4D). Accumulation of myofibroblasts is known to be associated with excessive extracellular matrix protein biosynthesis leading to organ-destructive remodeling. ${ }^{26}$ Consequently, we determined pulmonary collagen levels, as a hallmark of fibrosis. Figure 4D shows that collagen levels were increased by $160 \%$ in wild-type and $66 \%$ in PAR2-/- mice 14 days after bleomycin injection.

The prominent epithelial expression of PAR-2 prompted us to determine whether PAR-2 activation might also contribute to the progression of pulmonary fibrosis by modulating epithelial barrier function. As shown in Supplemental Figure S3 (available at $h$ ttp://ajp.amjpathol.org/), PAR-2 agonist peptide indeed increased epithelial barrier permeability by about $40 \%$ after 90 minutes of incubation and $50 \%$ after 4 hours of incubation.

PAR-2 deficiency might also protect against pulmonary fibrosis by limiting the inflammatory response. To prove or refute this hypothesis, we analyzed the inflammatory cell content of wild-type and PAR-2-/- BALF 7 days after bleomycin delivery, when the inflammatory response is known to be maximal. ${ }^{27}$ The total number of leukocytes in BALF increased about $500 \%$ in both PAR-
2-/- and wild-type mice (Figure 5A). Accordingly, macrophage and neutrophil counts were all increased to a similar extent (Figure 5, B and C), as were the lymphocyte counts (data not shown). Consistently, we did not detect any difference in inflammatory cell influx in the lung (Figure 5D). Moreover, although cytokines levels were increased by bleomycin treatment in wild-type and PAR$2-/-$ animals, there was no significant difference between the two groups of animals (data not shown). Therefore, PAR-2-dependent modulation of the inflammatory response seems not to be causally involved in bleomycin-induced pulmonary fibrosis, which is in line with a recent study, aiming at the role of PAR-2 in inflammation during acute lung injury. ${ }^{28}$

Because bleomycin administration is known to induce a procoagulant response in $B A L F,{ }^{29}$ we assessed the proliferative effect of BALF on murine fibroblasts. Indeed, murine fibroblasts seeded in BALF of wild-type mice treated with bleomycin showed enhanced survival of about $220 \%$, as compared to BALF of saline-treated mice (Figure 6A, top panel). Strikingly, BALF of bleomycintreated PAR-2-/- mice also increased fibroblast survival although to a lesser extent (by 148\%). Both TAP and hirudin diminished the effect of BALF derived from bleomycin-treated mice on fibroblast survival (Figure 6A, top panel). Again, as observed in Figure $1 \mathrm{C}$ with IPF patient BALF, hirudin seemed to have a greater effect on inhibition of cell viability than TAP. However, again, there was no statistical difference between the two groups. Interestingly, BALF of bleomycin-treated wild-type mice en- 
A

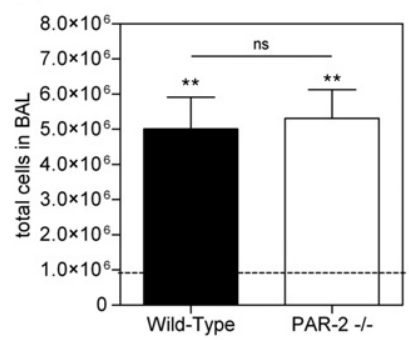

B

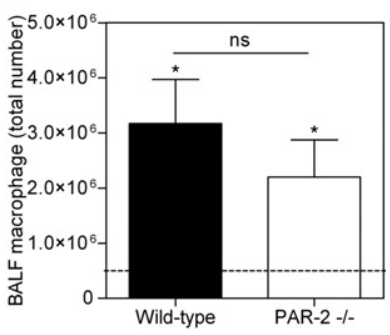

C

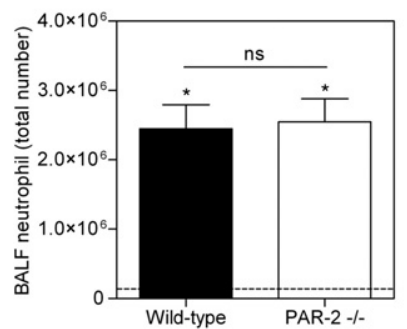

$\mathrm{D}$

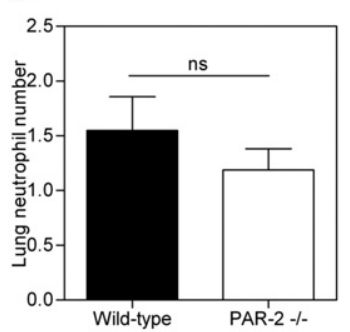

Figure 5. PAR-2 deficiency does not change the inflammatory response to bleomycin challenge. A: Total cell numbers and (B) macrophage and (C) neutrophil count in BALF of wild-type and PAR-2-/- mice in response to bleomycin instillation for 7 days. D: Neutrophil count in lung sections as determined by Ly- 6 scoring. Neutrophils were scored in 10 microscopic fields at a magnification of $\times 40$. A-D: Data represent the mean \pm SEM $(n=5-7$ mice per group). The dotted line represents baseline counts obtained in saline treated mice. ${ }^{*} P<0.05$ and ${ }^{* *} P<0.005$ for bleomycin versus saline treated mice. ns, not significant.

hanced viability of wild-type lung fibroblasts by about $59.9 \%$ but only by $15.8 \%$ when using PAR-2 deficient fibroblasts (Figure 6A, bottom panel). These data, which support our findings obtained with BALF from IPF patients (Figure 1A), establish that activation of the coagulation cascade appears to be causally linked with the observed proliferative effect of BALF.

Lung injury is well-known to increase vascular and epithelial permeability, resulting in extravasation of plasma proteins into the alveolar space, and subsequent activation of the coagulation cascade and deposition of fibrin clots. ${ }^{30}$ To assess whether the bleomycin-induced procoagulant activity in BALF correlated with fibrin deposition in the lung, we determined fibrin levels in wild-type and PAR-2-/- mice challenged with bleomycin. As shown in Figure 6, B and $\mathrm{C}$, bleomycin induced fibrin deposition in the lung. Interestingly, fibrin deposition seems to be primarily located in a transition zone between the less-affected parenchyma and the abnormal fibrotic lung, which is in line with the current hypothesis that fibroblast foci of pulmonary fibrosis are the leading edge of a complex reticulum that is highly interconnected and extends from the pleura into the underlying parenchyma. ${ }^{31}$.Fibrin levels in wild-type mice were significantly increased, compared to PAR-2-/- mice (Figure 6D). The difference in bleomycin-induced fibrin deposition between wild-type and PAR-2-/- mice might be explained by differential expression of TF. Hence, we determined TF levels in lung homogenates, showing that bleomycin strongly induced TF expression in wild-type mice, but not in PAR-2-/- mice (Figure 6E). Pulmonary
TF expression in the context of fibrosis thus seems to be PAR-2-dependent.

\section{Discussion}

A hypercoagulable state is frequently observed in patients with acute lung injury, which is most evident from increased procoagulant activity in BALF. ${ }^{9}$ Over recent years, this observation led to the hypothesis that uncontrolled activation of the coagulation cascade following lung injury would contribute to the development of lung inflammation and fibrosis in acute lung injury/acute respiratory distress syndrome and fibrotic lung disease. ${ }^{32,33}$ In the present study, we provide several lines of evidence strongly suggesting that PAR-2 is indeed important in the pathogenesis of lung fibrosis. We show that the coagulation cascade is indeed activated in the BALF of patients with idiopathic pulmonary fibrosis, the most devastating pulmonary fibrotic disease. Moreover, we established that, in the fibrotic part of the lung of these patients, PAR-2 (which can be activated by coagulation factors VIla and $\mathrm{Xa}$ ) is overexpressed. In a murine model of bleomycin-induced pulmonary fibrosis, we observed that genetic ablation of PAR-2 was beneficial, and significantly decreased fibroblast differentiation into myofibroblasts and subsequent extracellular matrix synthesis.

Our findings are in line with recent data showing that PAR-2 is a key player in the progression of tissue fibrosis. For instance, high expression of pulmonary PAR-2 is observed in acute and chronic lung injury, which led the authors to hypothesize that PAR-2 participates in inflammation and fibroproliferation during lung fibrosis. ${ }^{34}$ It is noteworthy, however, that our data (ie, similar inflammatory cell influx in wild-type and PAR-2-deficient mice) do not support a role for PAR-2 in inflammation (Figure 5). In renal interstitial fibrosis, $\alpha$-SM actin and PAR-2 expression are correlated, ${ }^{25}$ whereas PAR-2 expression is increased in biopsies of patients with IgA nephropathy. ${ }^{35}$ PAR-2 expression is also increased in chronic pancreatitis and in severe fibrosis accompanying pancreatic cancer. ${ }^{36}$ Finally, both FXa and PAR-2 are overexpressed in the kidney of rats subjected to experimental glomerulonephritis. Importantly, specific FXa inhibition is beneficial in rat model of mesangioproliferative glomerulonephritis, in part by reducing fibrin deposition. ${ }^{37}$ We recently showed FXa stimulated fibroblast proliferation, differentiation into myofibroblast and the expression of profibrotic proteins via PAR-2 activation. ${ }^{13}$ Next to a direct role on fibroblast activation during pulmonary fibrosis, PAR-2 activation may well aggravate fibrosis by modulating epithelial barrier functions. Indeed, epithelial barrier dysfunction contributes to fibrosis ${ }^{38-40}$ and PAR-2 activation seems to increase epithelial permeability in different organs. ${ }^{41-43}$ In the lung, PAR-2 activation causes a rapid and transient increase in permeability of airway epithelium that persists for 6 to 10 minutes. Our results support and extend these observations by showing that longer stimulation results in a persistent PAR-2-dependent increase in epithelial permeability (Supplemental Figure S3, http://ajp.amjpathol.org/). Finally, based on the remarkable PAR-2 expression pattern 
A
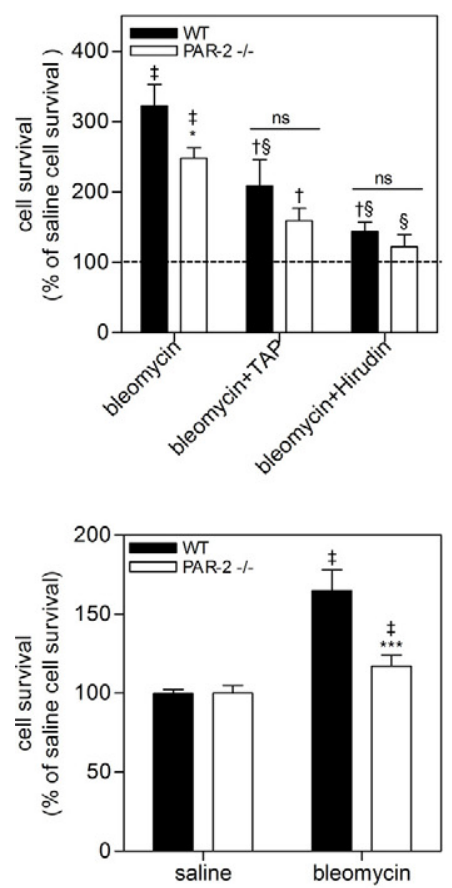

B

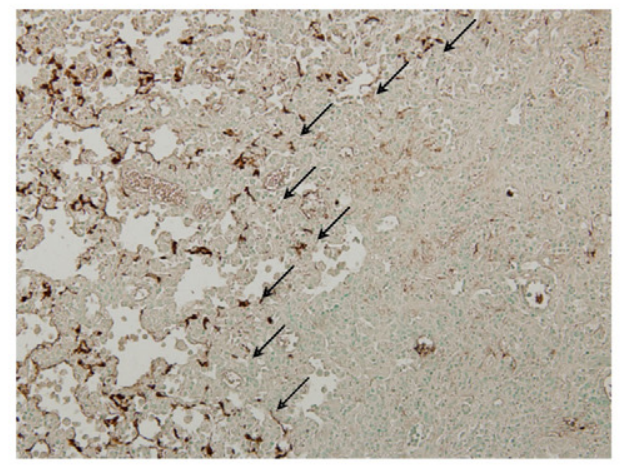

C

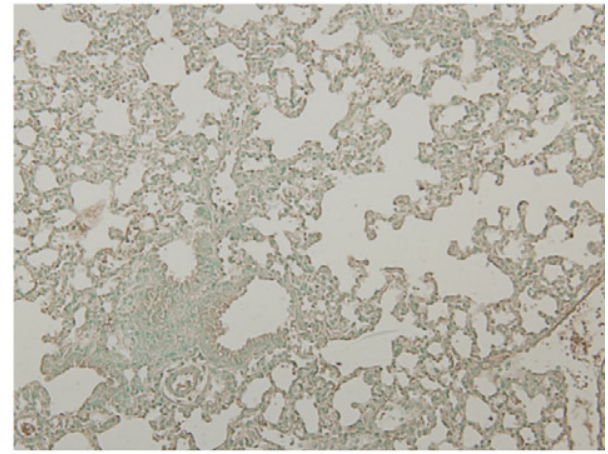

E

E wT
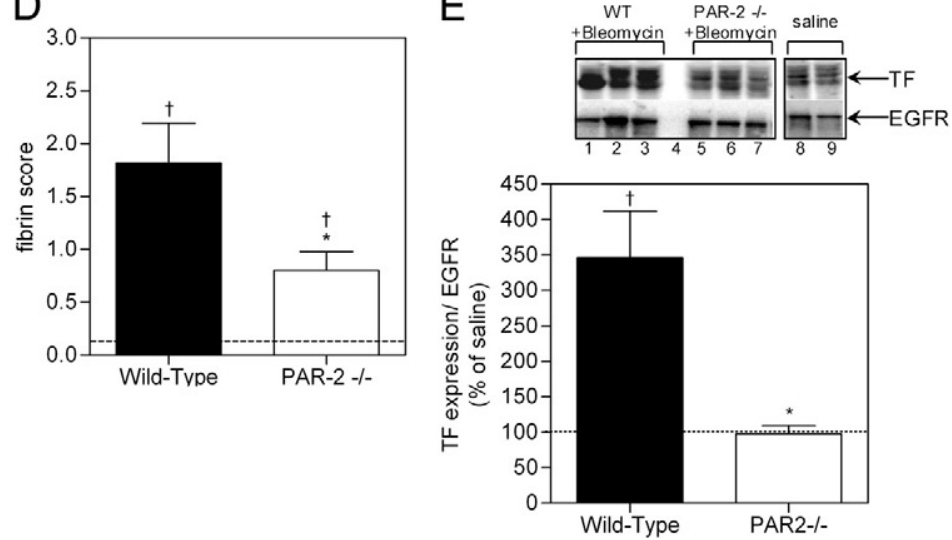

Figure 6. PAR-2 deficiency attenuates coagulation-dependent BALF-induced fibroblast survival, pulmonary fibrin deposition, and TF expression. A (top): Survival of murine fibroblasts induced (for 24 hours) by BALF of wild-type or PAR-2-/- mice treated for 14 days with bleomycin, in the presence or absence of TAP or hirudin. The results are shown as mean \pm SEM of percentage survival induced by BALF of saline treated mice (dotted line). Bottom: Survival of murine lung fibroblasts isolated from wild-type or PAR-2 -/ - mice induced (for 24 hours) by BALF of wild-type mice treated for 14 days with bleomycin. Shown are the mean \pm SEM. ${ }^{\dagger} P<0.05$ and ${ }^{\ddagger} P<0.005$ for BALF of bleomycin versus saline treated mice. ${ }^{*} P<0.05$ for BALF of bleomycin treated wild-type versus PAR- $2-/-$ mice. ${ }^{S} P<0.05$ for BALF of bleomycin-treated mice without TAP or hirudin versus BALF of bleomycin treated mice with TAP or hirudin. ns, no significant differences. B and C: Representative pictures of immunological staining of fibrin deposits (brown regions, arrows) in wild-type (B) and PAR-2-/- mice (C) 14 days after bleomycin instillation. D: Semiquantitative scoring of fibrin deposition in wild-type $(n=6)$ and PAR-2-/ $(n=7)$ animals 14 days after bleomycin instillation. E, top: Western blot analysis of TF expression in wild-type (lanes 1-3) and PAR-2-/- mice (lanes 5-7) 14 days after bleomycin or saline (wild-type, lane 8; PAR-2-/-, lane 9) treatment. Lane 4, marker. Epidermal growth factor receptor serves as a loading control. E, bottom: Quantification of TF expression in the lung of wild-type or PAR-2-/ - animals 14 days after bleomycin instillation. Shown are the mean \pm SEM of $n=4$ mice per group. A, D, and E: The dotted lines represent the mean expression in saline-treated mice. ${ }^{\dagger} P<0.05$ and ${ }^{\ddagger} P<0.005$ for bleomycin versus saline treated mice. ${ }^{*} P<0.05$ and ${ }^{* * * *} P<0.005$ for bleomycin treated wild-type versus PAR-2-/- mice. ns, non significant.

on the epithelium overlying fibroblastic foci, it is tempting to speculate that PAR-2 might also be involved in epithelialto-mesenchymal transition, a process which has emerged to be crucial in the progression of pulmonary fibrosis. ${ }^{44-46}$ Recent experiments in our laboratory support this latter hypothesis (manuscript in preparation).

Strikingly, our observation that PAR-2 deficiency did not modify the inflammatory response to bleomycin injury differs from observations on the effect of PAR-1 deficiency in a similar model of pulmonary fibrosis, where protection from pulmonary fibrosis in PAR-1-deficient animals was associated with decreased numbers of inflammatory cells in the BALF and reduced cytokine production. ${ }^{47}$ It is noteworthy that, similarly, in a murine model of crescentic glomerulonephritis, PAR-1 deficiency afforded protection from glomerulonephritis and associated fibrosis mainly by attenuating the inflammatory response, while PAR-2 deficiency protected from renal fibrosis without affecting inflammatory responses, such as leukocyte recruitment. Overall, these observations further emphasize the very distinct downstream re- sponses triggered by each receptor and are in line with the hypothesis that PAR-2 specifically elicits fibroproliferative programs. ${ }^{48}$

In line with previous observations that aSMA and PAR-2 expression is correlated in renal fibrosis, ${ }^{25}$ aSMA levels do not increase in PAR-2-deficient animals after bleomycin treatment. Interestingly however, PAR-2-deficient mice still develop fibrosis, as evident from abnormal lung histology (Figure 4). This is somehow puzzling, as aSMA is recognized as a hallmark of fibrotic diseases and is considered a indicator of disease severity. ${ }^{49} \mathrm{~A}$ potential explanation might be that, although the number of aSMA-positive myofibroblasts is similar in PAR-2-deficient mice treated with bleomycin or saline, the extracellular matrix producing capacity might be different. Alternatively, other cell types (such as epithelial cells undergoing transition into mesenchymal cells) might contribute to fibrosis. ${ }^{50,51}$ Finally, the observation that complete aSMA deficiency in myofibroblasts might even enhance fibrosis brings further complexity. ${ }^{52}$ 


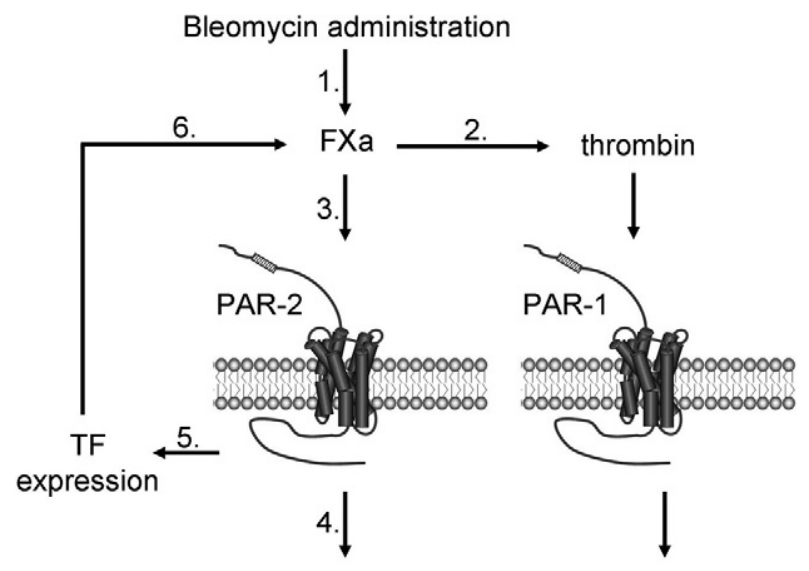

Fibroblast proliferation

Fibroblast differentiation

Fibrotic responses ECM synthesis

Figure 7. Proposed model for the role of PAR-2 and the coagulation cascade in pulmonary fibrosis. After activation of the coagulation cascade (1) in response to bleomycin administration, FXa induces fibrosis via thrombin generation and subsequent PAR-1 activation (2) or via PAR-2 dependent signaling (3). PAR-2 activation leads to direct fibroproliferative responses, such as fibroblast differentiation into myofibroblasts and extracellular matrix protein synthesis (4). PAR-2 activation also leads to TF expression (5), and subsequent reactivation of the coagulation cascade (6), ultimately leading to the establishment of a vicious cycle.

In the present study, we also observed that fibrin deposition was markedly reduced in the lungs of the PAR2-deficient mice, due to PAR-2-dependent modulation of tissue factor expression. Because excessive fibrin deposition in the lung is thought to contribute to fibrosis, ${ }^{9}$ one could argue that decreased fibrosis in PAR-2-deficient mice is a direct consequence of decreased fibrin deposition. However, two studies reported that fibrinogen-deficient animals are not protected against bleomycin-induced pulmonary fibrosis, suggesting that fibrin (ogen) is not essential for the development of bleomycininduced pulmonary fibrosis. ${ }^{53,54}$ These latter data argue against the hypothesis that fibrin deposition in the lung is a detrimental factor in pulmonary fibrosis.

Overall, our data point to a picture in which coagulation-driven PAR-2 activation induces pulmonary fibrosis, but is also associated with TF expression, thereby amplifying the coagulant response leading to FXa generation. At the crossroads between coagulation and signaling, FXa in turn may exert a dual role in fibrosis (Figure 7). First, via its procoagulant properties, it converts prothrombin into thrombin, inducing profibrotic and fibroproliferative effects via PAR-1 activation. ${ }^{16,47}$ Second, via direct PAR-2-dependent signaling, FXa triggers fibroproliferative responses like cell proliferation, extracellular matrix protein synthesis, cytokine production (ie, transforming growth factor- $\beta$, the most potent profibrotic cytokine ${ }^{55}$ ), fibroblast migration, and differentiation into myofibroblasts. ${ }^{13}$ In addition to TF-driven FXa generation, epithelial cells can express FX zymogen, as shown in a murine asthma model. ${ }^{56} \mathrm{FX}$ zymogen can subsequently be activated at the surface of macrophages present in inflamed tissue, ${ }^{57}$ thereby providing an additional source of pulmonary $\mathrm{FXa}$. Interestingly, $\mathrm{FXa}$ inhibition in the asthma model decreased lung collagen deposition. ${ }^{56}$
Further support for an important role of FXa-PAR-2 in fibrosis is derived from a rat model of mesangioproliferative glomerulonephritis showing that both FXa and PAR-2 are overexpressed and that specific FXa inhibition is beneficial. ${ }^{37}$ Moreover, a recent clinical study shows that Dalteparin (a FXa inhibitor) administration improved the survival of IPF patients. ${ }^{58}$ Because, to date, no PAR-2 antagonists are clinically available, the inhibition of FXa might be an interesting alternative therapeutic strategy.

Several issues should be kept in mind when interpreting the data. First, we used bleomycin to induce pulmonary fibrosis. This is the best characterized murine model for pulmonary fibrosis that triggers histological hallmarks (such as patchy parenchymal inflammation, epithelial cell injury with reactive hyperplasia, interstitial and intra-alveolar fibrosis, and the presence of clusters of spindle shaped mesenchymal cells) highly reminiscent of those observed in IPF patients. Moreover, both bleomycintreated animals and IPF patients present with activated coagulation. However, the bleomycin model also has some limitations, ${ }^{59}$ the first of which being that bleomycin induces fibrosis within days/weeks whereas fibrosis progresses over years in patients. In addition, bleomycininduced fibrosis is reversible and starts to regress after about 1 month, whereas fibrosis progresses irreversibly in IPF patients. Moreover, the chosen time points to analyze fibrosis might seem inappropriate at a first glance and several studies assessed fibrosis and 21 or 28 days after bleomycin instillation. However, time course analysis of the development of inflammation and fibrosis following bleomycin administration reported that the "switch" between inflammation and fibrosis appears to occur around days 7 to 9 after bleomycin administration. ${ }^{60,61}$ For instance, at day 6 already, the expression of profibrotic markers such as transforming growth factor- $\beta$ expression peaks, and collagen deposition (although weak) can already be observed by Masson's trichrome staining. We therefore decided to include a 7-day time point. The choice of day 14 as a later time point was also based on the above-mentioned time course studies of the development of fibrosis after bleomycin instillation. Importantly, these studies show that the most suitable time point for assessing lung fibrosis is day 14 after bleomycin challenge, as at this time point, the animals develop extensive fibrosis, but have less variability in the fibrotic response and lower mortality than at 21 days after administration. ${ }^{60,61}$ Second, quantitative assessment of collagen deposition was performed by Western blot analysis of collagen in whole lung homogenates with subsequent quantification of the specific signal and normalization to the loading control as described before. ${ }^{62,63}$ We specifically opted for this approach as it was previously shown to correlate perfectly with results obtained using hydroxyproline or Sircoll assays. ${ }^{63,64}$ Indeed, these latter assays are frequently used for quantitative assessment of collagen deposition, but (as a downside) they do not allow the analysis of additional markers (ie, PAR-2, aSMA, etc) on the dissected lung. Consequently, one would need to increase the number of experimental animals used when assessing hydroxyproline. Third, a recent paper by Su and Matthay ${ }^{28}$ suggested that PAR-2 might 
not be involved in pulmonary fibrosis, acute lung injury or lung infection. This apparent contradiction is puzzling; however, differences in the experimental set-up might provide explanations. For instance, the group size used in the Su and Matthay paper ${ }^{28}$ in the bleomycin studies was unusually small $(n=3)$ considering the variability when working with animal models and it significant differences might be difficult to obtain with such a small group size. Moreover, the authors pool the data obtained at day 7 and 14 which may impact on the outcome. Fourth, the histological scoring system which was used to quantitatively assess fibrosis is arguably subject to bias, such as sampling errors. To avoid such errors, we scored an average of 15 fields per slide. Moreover, we confirmed the Ashcroft data by Masson's trichrome and Sirius red staining, by aSMA immunohistochemical staining, by routine H\&E-staining and by quantitative assessment of fibrotic markers (collagen and aSMA). Finally, there is a disparity in age between the IPF patients and the healthy controls which may impact on the proliferative effect of the BALF (Figure 1). Although relatively little is known about the effects of aging on the composition of BALF in healthy individuals with a fully normal lung function an altered inflammatory cell profile in combination with lowgrade inflammation (among others an increased proportion of neutrophils; and higher interleukin-6 and interleukin-8 levels $\left.{ }^{6,66}\right)$ can be detected in individuals aged over 65 years as compared to young adults ( $<36$ years) (reviewed Sharma and Goodwin, 2006, ${ }^{67}$ ) probably due to repeated antigenic stimuli of the lower respiratory tract. ${ }^{68}$ We show, however, that fibroblast viability could be inhibited by the inhibition of coagulation, which actually raises the question whether activation of coagulation is age-dependent. Based on previous studies ${ }^{10,69}$ it can be concluded that this appears not to be the case. Therefore, although we cannot fully exclude a possible effect of aging on the activation of coagulation, it is highly unlikely that the differences observed are the mere consequence of aging.

In conclusion, our data show that PAR-2 may be involved in the pathogenesis of pulmonary fibrosis, and that inhibition of the PAR-2-coagulation axis may provide a novel therapeutic approach. The potential benefit of targeting the coagulation-PAR-2 axis is probably not restricted to pulmonary fibrosis, but might be appreciated in alternative fibrotic disorders in which coagulation cascade activation is observed.

\section{References}

1. Katzenstein AL, Myers JL: Idiopathic pulmonary fibrosis: clinical relevance of pathologic classification. Am J Respir Crit Care Med 1998, 157:1301-1315

2. Demedts M, Costabel U: ATS/ERS international multidisciplinary consensus classification of the idiopathic interstitial pneumonias. Eur Respir J 2002, 19:794-796

3. Swigris JJ, Kuschner WG, Kelsey JL, Gould MK: Idiopathic pulmonary fibrosis: challenges and opportunities for the clinician and investigator. Chest 2005, 127:275-283

4. Raghu G, Weycker D, Edelsberg J, Bradford WZ, Oster G: Incidence and prevalence of idiopathic pulmonary fibrosis. Am J Respir Crit Care Med 2006, 174:810-816
5. Scotton CJ, Chambers RC: Molecular targets in pulmonary fibrosis: the myofibroblast in focus. Chest 2007, 132:1311-1321

6. Hernandez-Rodriguez NA, Cambrey AD, Harrison NK, Chambers RC Gray AJ, Southcott AM, duBois RM, Black CM, Scully MF, McAnulty RJ, Laurent GJ: Role of thrombin in pulmonary fibrosis. Lancet 1995, 346:1071-1073

7. Imokawa S, Sato A, Hayakawa H, Kotani M, Urano T, Takada A: Tissue factor expression and fibrin deposition in the lungs of patients with idiopathic pulmonary fibrosis and systemic sclerosis. Am J Respir Crit Care Med 1997, 156:631-636

8. Gunther A, Mosavi P, Heinemann S, Ruppert C, Muth H, Markart P Grimminger F, Walmrath D, Temmesfeld-Wollbruck B, Seeger W: Alveolar fibrin formation caused by enhanced procoagulant and depressed fibrinolytic capacities in severe pneumonia. Comparison with the acute respiratory distress syndrome. Am J Respir Crit Care Med 2000, 161:454-462

9. Idell S: Coagulation, fibrinolysis, and fibrin deposition in acute lung injury. Crit Care Med 2003, 31:S213-S220

10. Gunther A, Mosavi P, Ruppert C, Heinemann S, Temmesfeld B, Velcovsky HG, Morr H, Grimminger F, Walmrath D, Seeger W: Enhanced tissue factor pathway activity and fibrin turnover in the alveolar compartment of patients with interstitial lung disease. Thromb Haemost 2000, 83:853-860

11. Wang J, Zheng H, Hollenberg MD, Wijesuriya SJ, Ou X, HauerJensen M: Up-regulation and activation of proteinase-activated receptor 2 in early and delayed radiation injury in the rat intestine: influence of biological activators of proteinase-activated receptor 2 . Radiat Res 2003, 160:524-535

12. Masamune A, Kikuta K, Satoh M, Suzuki N, Shimosegawa T: Protease-activated receptor-2-mediated proliferation and collagen production of rat pancreatic stellate cells. J Pharmacol Exp Ther 2005, 312:651-658

13. Borensztajn K, Stiekema J, Nijmeijer S, Reitsma PH, Peppelenbosch MP, Spek CA: Factor Xa stimulates proinflammatory and profibrotic responses in fibroblasts via protease-activated receptor-2 activation. Am J Pathol 2008, 172:309-320

14. American Thoracic Society/European Respiratory Society International Multidisciplinary Consensus Classification of the Idiopathic Interstitial Pneumonias: Joint statement of the American Thoracic Society (ATS), and the European Respiratory Society (ERS) adopted by the ATS board of directors, June 2001 and by the ERS Executive Committee, June 2001. Am J Respir Crit Care Med 2002, 165:277-304

15. Rijneveld AW, Florquin S, Bresser P, Levi M, De Waard V, Lijnen R, Van Der Zee JS, Speelman P, Carmeliet P, Van Der Poll T: Plasminogen activator inhibitor type-1 deficiency does not influence the outcome of murine pneumococcal pneumonia. Blood 2003, 102:934-939

16. Howell DC, Goldsack NR, Marshall RP, McAnulty RJ, Starke R, Purdy G, Laurent GJ, Chambers RC: Direct thrombin inhibition reduces lung collagen, accumulation, and connective tissue growth factor mRNA levels in bleomycin-induced pulmonary fibrosis. Am J Pathol 2001, 159:1383-1395

17. Leemans JC, Vervoordeldonk MJ, Florquin S, van Kessel KP, van der Poll T: Differential role of interleukin-6 in lung inflammation induced by lipoteichoic acid and peptidoglycan from Staphylococcus aureus. Am J Respir Crit Care Med 2002, 165:1445-1450

18. Ashcroft T, Simpson JM, Timbrell V: Simple method of estimating severity of pulmonary fibrosis on a numerical scale. J Clin Pathol 1988, 41:467-470

19. Theiss AL, Fuller CR, Simmons JG, Liu B, Sartor RB, Lund PK: Growth hormone reduces the severity of fibrosis associated with chronic intestinal inflammation. Gastroenterology 2005, 129:204-219

20. Slofstra SH, Cate HT, Spek CA: Low dose endotoxin priming is accountable for coagulation abnormalities and organ damage observed in the Shwartzman reaction. A comparison between a singledose endotoxemia model and a double-hit endotoxin-induced Shwartzman reaction. Thromb J 2006, 4:13

21. Trejo J, Connolly AJ, Coughlin SR: The cloned thrombin receptor is necessary and sufficient for activation of mitogen-activated protein kinase and mitogenesis in mouse lung fibroblasts. Loss of responses in fibroblasts from receptor knockout mice. J Biol Chem 1996, 271:21536-21541

22. Lieber M, Smith B, Szakal A, Nelson-Rees W, Todaro G: A continuous tumor-cell line from a human lung carcinoma with properties of type II alveolar epithelial cells. Int J Cancer 1976, 17:62-70 
23. Patterson CE, Rhoades RA, Garcia JG: Evans blue dye as a marker of albumin clearance in cultured endothelial monolayer and isolated lung. J Appl Physiol 1992, 72:865-873

24. Blanc-Brude OP, Archer F, Leoni P, Derian C, Bolsover S, Laurent GJ, Chambers RC: Factor Xa stimulates fibroblast procollagen production, proliferation, and calcium signaling via PAR1 activation. Exp Cell Res 2005, 304:16-27

25. Xiong J, Zhu Z, Liu J, Wang Y, Li Z: Role of protease activated receptor-2 expression in renal interstitial fibrosis model in mice. $J$ Huazhong Univ Sci Technolog Med Sci 2005, 25:523-526

26. Serini G, Gabbiani G: Mechanisms of myofibroblast activity and phenotypic modulation. Exp Cell Res 1999, 250:273-283

27. Janick-Buckner D, Ranges GE, Hacker MP: Alteration of bronchoalveolar lavage cell populations following bleomycin treatment in mice. Toxicol Appl Pharmacol 1989, 100:465-473

28. Su X, Matthay MA: Role of protease activated receptor 2 in experimental acute lung injury and lung fibrosis. Anat Rec (Hoboken) 2009, 292:580-586

29. Idell S, Gonzalez KK, MacArthur CK, Gillies C, Walsh PN, McLarty J, Thrall RS: Bronchoalveolar lavage procoagulant activity in bleomycininduced lung injury in marmosets. Characterization and relationship to fibrin deposition and fibrosis. Am Rev Respir Dis 1987, 136:124-133

30. Moore BB, Hogaboam CM: Murine models of pulmonary fibrosis. Am J Physiol Lung Cell Mol Physiol 2008, 294:L152-L160

31. Cool CD, Groshong SD, Rai PR, Henson PM, Stewart JS, Brown KK: Fibroblast foci are not discrete sites of lung injury or repair: the fibroblast reticulum. Am J Respir Crit Care Med 2006, 174:654-658

32. Wygrecka M, Jablonska E, Guenther A, Preissner KT, Markart P: Current view on alveolar coagulation and fibrinolysis in acute inflammatory and chronic interstitial lung diseases. Thromb Haemost 2008, 99:494-501

33. Chambers RC: Procoagulant signalling mechanisms in lung inflammation and fibrosis: novel opportunities for pharmacological intervention? Br J Pharmacol 2008, 153 Suppl 1:S367-S378

34. Cederqvist K, Haglund C, Heikkila P, Hollenberg MD, Karikoski R, Andersson S: High expression of pulmonary proteinase-activated receptor 2 in acute and chronic lung injury in preterm infants. Pediatr Res 2005, 57:831-836

35. Grandaliano G, Pontrelli P, Cerullo G, Monno R, Ranieri E, Ursi M, Loverre A, Gesualdo L, Schena FP: Protease-activated receptor-2 expression in IgA nephropathy: a potential role in the pathogenesis of interstitial fibrosis. J Am Soc Nephrol 2003, 14:2072-2083

36. Ikeda O, Egami H, Ishiko T, Ishikawa S, Kamohara H, Hidaka H, Mita $\mathrm{S}$, Ogawa M: Expression of proteinase-activated receptor-2 in human pancreatic cancer: a possible relation to cancer invasion and induction of fibrosis. Int J Oncol 2003, 22:295-300

37. Nomura K, Liu N, Nagai K, Hasegawa T, Kobayashi I, Nogaki F, Tanaka M, Arai H, Fukatsu A, Kita T, Ono T: Roles of coagulation pathway and factor $\mathrm{Xa}$ in rat mesangioproliferative glomerulonephritis. Lab Invest 2007, 87:150-160

38. Strieter RM, Mehrad B: New mechanisms of pulmonary fibrosis. Chest 2009, 136:1364-1370

39. Lee DB, Huang E, Ward HJ: Tight junction biology and kidney dysfunction. Am J Physiol Renal Physiol 2006, 290:F20-F34

40. Rieder F, Fiocchi C: Intestinal fibrosis in IBD-a dynamic, multifactorial process. Nat Rev Gastroenterol Hepatol 2009, 6:228-235

41. Bueno L, Fioramonti J: Protease-activated receptor 2 and gut permeability: a review. Neurogastroenterol Motil 2008, 20:580-587

42. Chin AC, Lee WY, Nusrat A, Vergnolle N, Parkos CA: Neutrophilmediated activation of epithelial protease-activated receptors-1 and -2 regulates barrier function and transepithelial migration. J Immunol 2008, 181:5702-5710

43. Hachem JP, Houben E, Crumrine D, Man MQ, Schurer N, Roelandt T, Choi EH, Uchida Y, Brown BE, Feingold KR, Elias PM: Serine protease signaling of epidermal permeability barrier homeostasis. J Invest Dermatol 2006, 126:2074-2086

44. Willis BC, duBois RM, Borok Z: Epithelial origin of myofibroblasts during fibrosis in the lung. Proc Am Thorac Soc 2006, 3:377-382

45. Eickelberg O, Selman M: Update in diffuse parenchymal lung disease 2009. Am J Respir Crit Care Med 2009, 181:883-888

46. Konigshoff M, Eickelberg O: WNT signaling in lung disease: a failure or a regeneration signal? Am J Respir Cell Mol Biol 2010, 42:21-31

47. Howell DC, Johns RH, Lasky JA, Shan B, Scotton CJ, Laurent GJ,
Chambers RC: Absence of proteinase-activated receptor-1 signaling affords protection from bleomycin-induced lung inflammation and fibrosis. Am J Pathol 2005, 166:1353-1365

48. Materazzi S, Pellerito S, Di Serio C, Paglierani M, Naldini A, Ardinghi C, Carraro F, Geppetti P, Cirino G, Santucci M, Tarantini F, Massi D: Analysis of protease-activated receptor-1 and -2 in human scar formation. J Pathol 2007, 212:440-449

49. Tomasek JJ, Gabbiani G, Hinz B, Chaponnier C, Brown RA: Myofibroblasts and mechano-regulation of connective tissue remodelling. Nat Rev Mol Cell Biol 2002, 3:349-363

50. Kim KK, Kugler MC, Wolters PJ, Robillard L, Galvez MG, Brumwell AN, Sheppard D, Chapman HA: Alveolar epithelial cell mesenchymal transition develops in vivo during pulmonary fibrosis and is regulated by the extracellular matrix. Proc Natl Acad Sci USA 2006 , 103:13180-13185

51. Tanjore H, Xu XC, Polosukhin VV, Degryse AL, Li B, Han W, Sherril TP. Plieth D, Neilson EG, Blackwell TS, Lawson WE: Contribution of epithelial-derived fibroblasts to bleomycin-induced lung fibrosis. Am J Respir Crit Care Med 2009, 180:657-665

52. Takeji M, Moriyama T, Oseto S, Kawada N, Hori M, Imai E, Miwa T: Smooth muscle alpha-actin deficiency in myofibroblasts leads to enhanced renal tissue fibrosis. J Biol Chem 2006, 281:40193-40200

53. Hattori N, Degen JL, Sisson TH, Liu H, Moore BB, Pandrangi RG, Simon RH, Drew AF: Bleomycin-induced pulmonary fibrosis in fibrinogen-null mice. J Clin Invest 2000, 106:1341-1350

54. Ploplis VA, Wilberding J, McLennan L, Liang Z, Cornelissen I, DeFord ME, Rosen ED, Castellino FJ: A total fibrinogen deficiency is compatible with the development of pulmonary fibrosis in mice. Am J Pathol 2000, 157:703-708

55. Border WA, Noble NA: Transforming growth factor beta in tissue fibrosis. N Engl J Med 1994, 331:1286-1292

56. Shinagawa K, Martin JA, Ploplis VA, Castellino FJ: Coagulation factor Xa modulates airway remodeling in a murine model of asthma. Am $J$ Respir Crit Care Med 2007, 175:136-143

57. Pejler G, Lunderius C, Tomasini-Johansson B: Macrophages synthesize factor $\mathrm{X}$ and secrete factor $\mathrm{X} / \mathrm{Xa}$-containing prothrombinase activity into the surrounding medium. Thromb Haemost 2000, 84:429-435

58. Kubo H, Nakayama K, Yanai M, Suzuki T, Yamaya M, Watanabe M, Sasaki H: Anticoagulant therapy for idiopathic pulmonary fibrosis. Chest 2005, 128:1475-1482

59. Chua F, Gauldie J, Laurent GJ: Pulmonary fibrosis: searching for model answers. Am J Respir Cell Mol Biol 2005, 33:9-13

60. Izbicki G, Segel MJ, Christensen TG, Conner MW, Breuer R: Time course of bleomycin-induced lung fibrosis. Int J Exp Pathol 2002, 83:111-119

61. Chaudhary NI, Schnapp A, Park JE: Pharmacologic differentiation of inflammation and fibrosis in the rat bleomycin model. Am J Respir Crit Care Med 2006, 173:769-776

62. Zhao L, Xiao K, Wang H, Wang Z, Sun L, Zhang F, Zhang X, Tang F, $\mathrm{He}$ W: Thalidomide has a therapeutic effect on interstitial lung fibrosis: evidence from in vitro and in vivo studies. Clin Exp Immunol 2009, 157:310-315

63. Fang HL, Lai JT, Lin WC: Inhibitory effect of olive oil on fibrosis induced by carbon tetrachloride in rat liver. Clin Nutr 2008, 27:900-907

64. Nakao A, Fujii M, Matsumura R, Kumano K, Saito Y, Miyazono K, Iwamoto I: Transient gene transfer and expression of Smad7 prevents bleomycin-induced lung fibrosis in mice. J Clin Invest 1999, 104:5-11

65. Meyer KC, Ershler W, Rosenthal NS, Lu XG, Peterson K: Immune dysregulation in the aging human lung. Am J Respir Crit Care Med 1996, 153:1072-1079

66. Meyer KC, Rosenthal NS, Soergel P, Peterson K: Neutrophils and low-grade inflammation in the seemingly normal aging human lung. Mech Ageing Dev 1998, 104:169-181

67. Sharma G, Goodwin J: Effect of aging on respiratory system physiology and immunology. Clin Interv Aging 2006, 1:253-260

68. Meyer KC, Soergel P: Variation of bronchoalveolar lymphocyte phenotypes with age in the physiologically normal human lung. Thorax 1999, 54:697-700

69. Fujii M, Hayakawa H, Urano T, Sato A, Chida K, Nakamura H, Takada A: Relevance of tissue factor and tissue factor pathway inhibitor for hypercoagulable state in the lungs of patients with idiopathic pulmonary fibrosis. Thromb Res 2000, 99:111-117 